\title{
European Academy of Neurology (EAN) - The First Congress Is Approaching
}

\author{
Anna Sauerbier \\ Clinical Research Fellow, National Parkinson Foundation International Centre of Excellence, King's College Hospital, London, UK
}

Disclosure: Anna Sauerbier is a member of the European Academy of Neurology (EAN) Liaison committee and an active member of the European Association of Young . Neurologists and Trainees (EAYNT). Anna Sauerbier has no conflicts of interest to declare. No funding was received for the publication of this article. open Access: This article is published under the Creative Commons Attribution Noncommercial License, which permits any non-commercial use, distribution, adaptation and reproduction provided the original author(s) and source are given appropriate credit.

Received: 20 March 2015 Accepted: 2 April 2015 Citation: European Neurological Review, 2015;10(1):10-1 DOl: 10.17925/ENR.2015.10.01.10

Correspondence: Anna Sauerbier, Department of Neurology, 9th Floor, Ruskin Wing, King's College Hospital, Denmark Hill, London SE5 9RS, UK. E: annasauerbier@nhs.net

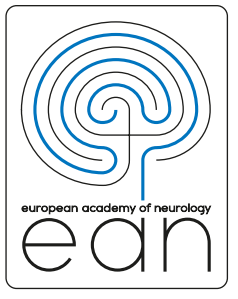

The inauguration of the single and novel European Academy of Neurology (EAN) took place in Istanbul, Turkey, in June 2014 during the first and last Joint Congress of European Neurology, joining both the European Federation of Neurological Societies (EFNS) and European Neurological Society (ENS). ${ }^{1}$

The five main values of professionalism, high ethical standards, involvement, independence and transparency will guide the EAN to broaden the growing field of neurology to make it one of the major medical specialities with both high clinical and research standards throughout the European countries, pursuing the academy's main goal of promoting excellence in neurology in Europe. ${ }^{1,2}$

Currently, the EAN represents more than 21,000 European neurologists, including around 45 registered European national neurological societies as well as 800 individuals and nine associate member societies. ${ }^{2}$

The head office of the EAN is located in the former EFNS head office in the cultural Museum District of Vienna, Austria. EAN, being created according to Austrian law, is a novel society that additionally covers the already established programmes, functions and initiatives of both its parent societies (EFNS and ENS). This combination will provide an effective means of collaborations and ensure the smooth functioning of the different sectors of the organisation.

In June 2014, the first EAN board was elected by the assembly of delegates, unifying institutional and individual delegates:

- President: Professor Günther Deuschl, Kiel, Germany

- Vice President: Professor Franz Fazekas, Graz, Austria

- Secretary General: Professor Didier Leys, Lille, France

- Treasurer: Professor Marianne de Visser, Amsterdam, The Netherlands

- Member at Large: Professor Per Soelberg Sørensen, Copenhagen, Denmark

Furthermore, the EAN includes four different committees and their representing chairs:
- Chair Liaison Committee: Professor David B. Vodušek, Ljubljana, Slovenia

- Chair Scientific Committee: Professor Antonio Federico, Siena, Italy

- Chair Education Committee: Dr Hannah Cock, London, UK

- Chair Congress Programme Committee: Professor Paul Boon, Gent, Belgium

After the inauguration of the EAN, all committees were restructured to include members from the previously active EFNS/ENS committees of same name, with a significant number of new representatives from all over Europe balancing the representation of both.

The EAN is conscious that to establish "excellence in neurology in Europe", the different national schools of neurology, and the wide range of different cultures of practising neurology, must be respected and integrated within the EAN. ${ }^{1}$

Considering that our population is further ageing, the diagnosis and treatment of neurological diseases will need to adapt and improve to ensure the best possible management of neurological conditions. To develop methods for dealing with the challenge of the increasing burden and costs of the neurological conditions in Europe, the EAN must represent a strong leadership in the field of neurology and collaborate with the European commission and the European Parliament.3.,4

The first Congress of the EAN will take place in Berlin, Germany, 20-23 June 2015, bringing together more than 6,000 delegates from all over the world to learn and discuss the exciting speciality that is neurology. ${ }^{2}$ Owing to the history of Berlin as a reunited city, the EAN thought Berlin a symbolic place to host the very first congress of the united voice of European neurology, the EAN. The final programme is very diverse and rich, reflecting the excellent quality of European neurology. In future, the EAN congress will be held annually, covering the entire field of research and health care developments in neurology to provide a profound state-of-the-art update. The EAN is dedicated to providing the highest quality in clinical care and in research in neurology. ${ }^{1,2}$

Furthermore, neurology residents will have the noteworthy opportunity to undertake a European final examination, the European 
Union of Medical Specialists (UEMS)/European Board of Neurology (EBN) examination to become a fellow of the European board of Neurology, another step towards harmonising post-graduate education in Europe. ${ }^{5}$

Because the newly formed society is also focusing on improving communication among young neurologists and directly involving and exciting them about the constantly evolving field of neurology, the EAN has already initiated closer collaborations with the European
Association of Young Neurologists and Trainees (EAYNT) who will be present during the EAN in Berlin. ${ }^{6}$

All this would not have been possible without the benefit of notable groundwork on the part of the EFNS and ENS, nor without the hardworking team leading the EAN. Having already achieved a considerable amount of progress since its inauguration in June 2014, the EAN looks forward to exciting new developments and challenges - starting with the forthcoming EAN congress in Berlin, Germany, in June 2015

1. Bassetti CL, Hughes R, The European Academy of Neurology is founded: a fundamental step linking the glorious past with our future challenges, Eur J Neurol, 2014;21:809-13. European Academy of Neurology (www.eaneurology.org).

Olesen J, Gustavsson A, Svensson M, et al., The economic cost of brain disorders in Europe, Eur J Neurol, 2012:19:155-62.

Council decision of 3 December 2013 establishing the specific programme implementing Horizon 2020 - the Framework Programme for Research and Innovation (2014-2020) and repealing Decisions 2006/971/EC.

5. Available at: http://www.uems-neuroboard.org/ebn/ (accessed 8 April 2015).

6. Available at: www.eaynt.org (accessed 8 April 2015). 